\title{
REVISÕES, REVISORES E A CAPES
}

Em 10 de novembro de 2007, a RAM B inaugurou o seu novo sistema de submissão eletrônica (www.ramb.org. $\mathrm{br} / \mathrm{sgp} /$ ). 0 objetivo foi adequar-se a uma demanda maior e às exigências de critérios mais rígidos de seleção, relacionados à crescente qualidade dos artigos submetidos, fruto da indexação da RAM B no ISI W eb of Science (Science Citation Index Expanded).

Paralelamente, o Conselho Editorial resolveu incorporar ao sistema de submissão ferramentas que permitam localizar artigos publicados em periódicos SciELO com as mesmas palavraschave fornecidas pelo autor ${ }^{1}$. De maneira ágil e simples, autores, revisores e editores podem investigar a originalidade e fomentar a discussão do tema, sugerindo a leitura e eventualmente citando artigos da base SciELO . O s resultados apareceram rapidamente: dos 20 artigos submetidos mensalmente passamos a receber 45. Aqueles que passaram pela seleção inicial, baseada nos critérios da revista (w w w. ramb.org.br/sgp/ naveg/criterios.asp) foram enviados para 227 revisores.

Entretanto, como demonstra a Figura 1, menos de $40 \%$ dos revisores realizaram 0 trabalho. Menor ainda foi a porcentagem de revisões entregues dentro do prazo solicitado. 0 Conselho Editorial da RAM B tem enorme respeito pela colaboração, desprendimento e espírito altruísta dos revisores da revista. Desde a introdução do novo sistema de submissão, toda vez que uma revisão não é entregue no prazo ou não é aceita, a seguinte mensagem é enviada: "Lamentamos que não tenha sido possível contar com sua preciosa análise. Entretanto, sabemos das inúmeras atribuições dos pesquisadores e esperamos contar com você para futuras avaliações."

A exemplo de outros periódicos brasileiros e internacionais, a RAMB publica, ao final de cada volume, os nomes dos pesquisadores que colaboraram na revisão de artigos

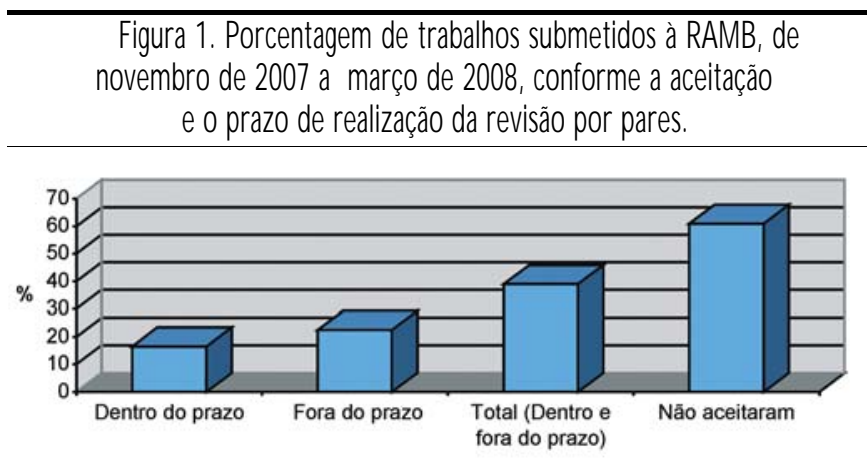

submetidos. Por outro lado, o aumento da quantidade e da qualidade das submissões e a pressão por parte dos programas de pós-graduação (os maiores fomentadores da produção científica em medicina) pela agilização no processo de revisão por pares, exigem uma reformulação.

Ao mesmo tempo, a RAM B sugere que a CAPES adote estes registros como certificad os da participação de orientadores e de alunos (sob supervisão dos primeiros) dentro dos critérios de avaliação dos programas de pós-graduação. Acreditamos que, a um só tempo, a CAPES estará estimulando a formação e o espírito crítico dos jovens pesquisadores, premiando 0 altruísmo dos revisores e fomentando a troca de experiências entre pesquisadores brasileiros, o que só poderá resultar no incremento do fator de impacto de nossas publicações.

Bruno Caramelli

Referências

Deheinzelin D, Caramelli B. Produção científica, pós-graduação e a Ramb. Rev. Assoc. Med. Bras. 2007; 53(6): 471-2. 